\title{
Article
}

\section{Strategi Petani Dalam Membangun Kekuatan Politik Petani Subsektor Perkebunan Komoditi Kelapa Sawit Kecamatan Pelepat Ilir Kabupaten Bungo}

\author{
Mulia Jaya ${ }^{*}$, Mimiyanti ${ }^{2}$
}

This article is an open access article distributed under the terms and conditions of the Creative Commons Attribution-ShareAlike 4.0 International (CC BY SA ) License (https://creativecommo ns.org/licenses/bysa/4.0/).

\section{Jurnal Politik dan} Pemerintahan Daerah ISSN 2686-2271

Fakultas Ilmu Sosial dan Ilmu Politik, Universitas Muara Bungo Jl. Diponegoro No. 27, Muara Bungo-Jambi, (0747) 323310

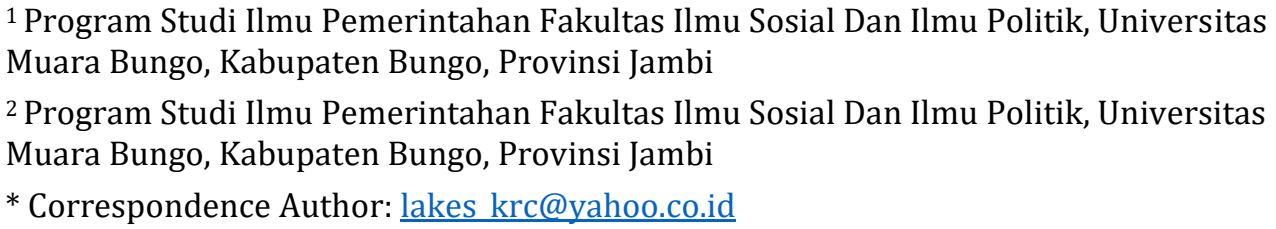

Abstract: Most of the Indonesian population lives in rural areas and pursues livelihoods in the agricultural and plantation sectors. One of the sectors developed by the government and has a large role in agriculture is the plantation sector. One of the growing and global sectors in Indonesia today is Palm Oil. Palm oil is an alternative job and income in rural areas such as in Pelepat Ilir sub-district, Bungo Regency. This study aims to find out how farmers' strategies are in building the political power of farmers in the oil palm plantation sub-sector and to find out the obstacles faced by farmers. The research method is a descriptive method with qualitative data analysis. From the results of the study, it is known that the strategies used by farmers in building the political power of farmers are Communication strategies which include (power and socialization), and Organizational Forming Strategies. The obstacles faced by farmers are the lack of cohesiveness with each other and the absence of guidance from the local government.

Keywords: Strategy, Farmers, Political Power, Oil Palm

Abstrak: Penduduk indonesia sebagian besar tinggal di wilayah perdesaan dan menekuni sumber mata pencaharian disektor pertanian dan perkebunan. Salah satu sektor yang di kembangkan oleh pemerintah dan cukup besar perannya dalam pertanian adalah sektor perkebunan. Salah satu sektor yang berkembang dan mendunia di indonesia saat ini adalah Kelapa Sawit. Kelapa sawit menjadi alternatif pekerjaan dan penghasilan di Pedesaan seperti di kec.Pelepat Ilir Kabupaten Bungo. Penelitian ini bertujuan untuk mengetahui bagaimana strategi petani dalam membangun kekuatan politik petani sub sektor perkebunan komoditi kelapa sawit dan untuk mengetahui kendala-kendala yang dihapi para petani. Metode Penelitian adalah metode deskriptif dengan analisa data kualitatif. Dari hasil penelitian diketahui bahwa strategi yang digunakan petani dalam membangun kekuatan politik petani adalah strategi Komunikasi yang meliputi (kekuasaan dan sosialisasi), dan Strategi Pembentukan Organisasi. Adapun kendala-kendala yang dihadapi petani adalah Kurangnya kekompakan terhadap satui sama lain dan tidak adanya pembinaan dari pemerintah daerah.

Kata Kunci: Strategi, Petani, Kekuatan Politik, Kelapa Sawit 


\section{Pendahuluan}

Penduduk Indonesia sebagian besar tinggal di wilayah perdesaan dan menekuni sumber mata pencaharian di sektor pertanian dan perkebunan. Menurut Badan Pusat Statistik tahun 2010 ada sebanyak 50,21 persen (119.321.070 jiwa) dari 237.641.326 jiwa penduduk Indonesia yang tinggal di perdesaan yang bekerja di sektor pertanian. Badan Pusat Statistik tahun 2012 mencatat sekitar 36,5 persen (41,20 juta orang) dari 112,80 juta jiwa penduduk yang bekerja di sektor pertanian termasuk sebagai buruh tani. Karena itu sektor pertanian tetap penting bagi perekonomian rakyat Indonesia. Bagi negara agraris seperti Indonesia, sektor pertanian sangat penting dalam mendukung perekonomian negara selain sebagai penyedia lapangan pekerjaan, sandang, pangan, dan papan bagi masyarakat Indonesia juga sebagai salah satu sektor penghasil komoditas ekspor nonmigas untuk devisa negara(Adimihardja, 2006).

Salah satu sektor yang dikembangkan oleh pemerintah dan cukup besar peranannya dalam pertanian adalah sektor perkebunan. Sub sektor perkebunan menunjukkan ketangguhannya dalam menghadapi krisis ekonomi. Hal ini karena hasil dari sub sektor perkebunan mengalami peningkatan harga sebagai dampak dari perbedaan nilai tukar rupiah terhadap dollar AS. Sejak pertengahan tahun 1970-an pertumbuhan sektor perkebunan terus dipicu melalui berbagai kebijakan baik produksi, investasi, ekspor, dan berbagai kebijakan lainnya. Hal ini dilakukan karena dengan sumberdaya domestik yang dikandungnya, sektor perkebunan ini dinilai memiliki keunggulan komparatif di pasar domestik dan internasional (Siyamitri, 2009).

Sektor perkebunan yang berkembang dan mendunia di Indonesia saat ini menurut BPS 2013 yaitu perkebunan rempah-rempah, perkebunan kakao, perkebunan karet, perkebunan kopi, perkebunan teh, perkebunan tembakau dan perkebunan kelapa sawit. Salah satu perkebunan terpenting di Indonesia adalah perkebunan kelapa sawit. Pada tahun 2012 saja perkebunan kelapa sawit telah mencapai seluas 9,230,100 Ha (Afrizal,2015 ).

Bagi Indonesia, tanaman kelapa sawit mempunyai arti penting bagi pembangunan perkebunan nasional. Selain mampu menciptakan kesempatan kerja yang mengarah pada kesejahteraan masyarakat, juga sebagai sumber perolehan devisa negara. Indonesia merupakan salah satu produsen utama minyak sawit di dunia. Perkembangan kelapa sawit di Indonesia didukung oleh kondisi klimat Indonesia yang sangat sesuai untuk keberlangsungan hidup tanaman kelapa sawit (Elisabeth \& Ginting, 2003).

Kelapa sawit pertama kali diperkenalkan di Indonesia oleh pemerintah kolonia Belanda pada tahun 1848. Ketika itu ada empat batang bibit kelapa sawit yang dibawa dari Mauritius dan Amsterdam dan ditanam di kebun Raya Bogor. Tanaman kelapa sawit mulai diusahakan dan dibudidayakan secara komersial pada tahun 1911. Perintis usaha perkebunan kelapa sawit di Indonesia adalah Adrien Hallet, seorang Belgia yang telah belajar banyak tentang kelapa sawit di Afrika. Budi daya yang dilakukan diikuti oleh K.scadt yang menandai lahirnya perkebunan kelapa sawit di Indonesia. Sejak saat itu perkebunan kelapa sawit di Indonesia mulai berkembang. Perkebunan kelapa sawit pertama kali berlokasi di pantai Timur Sumatra (Deli) dan Aceh.

Setelah Belanda dan Jepang meninggalkan Indonesia, pada tahun 1957, pemerintah mengambil alih perkebunan dengan alasan politik dan keamanan. Pemerintah menempatkan perwira-perwira militer disetiap manajemen perkebunan yang bertujuan mengamankan jalannya produksi. Memasuki pemerintah orde baru, pembangunan perkebunan diarahkan dalam rangka menciptakan kesempatan kerja, meningkatkan kesejahteraan masyarakat, dan 
sebagai sektor penghasil devisa negara. Sejak saat itu, lahan perkebunan kelapa sawit Indonesia berkembang pesat terutama perkebunan rakyat.

Sekarang pasar untuk kelapa sawit telah tumbuh dengan pesat, terutama di sejumlah negara seperti India, Cina dan negara Eropa Timur. Untuk memenuhi kebutuhan pasar tersebut, produksi kelapa sawit diperkirakan akan berlipat ganda dalam kurun waktu dua puluh tahun kedepan yang tentu saja memerlukan pertambahan lahan perkebunan. Perkebunan kelapa sawit di Indonesia tidak hanya bertambah luas wilayahnya namun juga mengalami perubahan yang cukup besar dalam hal pemilikan. Pada awal perkembangannya, perkebunan kelapa sawit dikelolah secara dominan oleh negara (BUMN) yang pendanaannya bersumber dari pinjaman yang diperoleh dari Bank Dunia, Uni Eropa dan Bank Pembangunan Asia (ADB). Selama dekada 1970-an dan 1980-an, perluasan perkebunan kelapa sawit terfokus pada pembangunan perkebunan yang terdapat dalam program pemerintah di bidang transmigrasi (PIR-Trans), di mana badan usaha memiliki negara mengontrol perkebunan inti yang dikelilingi oleh wilayah perkebunan plasma seluas 2 sampai 5 hektare, yang dikelolah oleh para transmigrasi maupun penduduk setempat.

Pertanian menjadi pemenuhan kebutuhan bagi masyarakat pedesaan, terutama pada masyarakat Kabupaten Bungo. Masyarakat setempat umumya mempunyai sumber pencarian bertani yaitu pertanian kebun kelapa sawit dan karet. Salah satu subsektor yang cukup besar peranannya dalam pertanian adalah subsektor perkebunan. Subsektor perkebunan menunjukkan ketangguhannya dalam menghadapi krisis ekonomi.

Masyarakat Kabupaten Bungo kehidupan perekonominya bertumpu pada perkebunan yaitu perkebunan kelapa sawit dan kebun karet, namun yang mendominasi adalah perkebunan kelapa sawit. Pada tahun 1990-an masyarakat Kabupaten Bungo yang tinggal di beberapa desa Yang ada di Kabupaten Bungo mayoritas bermata pencaharian sebagai petani sawah, setelah masuknya program pemerintah dengan kebijakan PIR (Perusahaan Inti Rakyat) tersebut menyebabkan terjadinya perubahan terhadap sumber mata pencaharian, menjadi petani kelapa sawit. Kelapa sawit merupakan salah satu usaha tani dalam bidang perkebunan yang berorientasi ekspor. Permintaan terhadap komonditas kelapa sawit tingkat internasional dan nasional masih tinggi. Karena itu usaha tani kelapa sawit banyak dilakukan oleh masyarakat maupun pengusaha untuk mendapat keuntungan yang tinggi. Pada mulanya usaha tani kelapa sawit dilakukan oleh perusahaan dalam upaya pemerataan penduduk melalui kegiatan transmigrasi. Usaha tani kelapa sawit pelaksanaannya berupa program pola Perusahaan Inti Rakyat (dikenal dengan pola PIR). Dalam kegiatan tersebut perusahaan yang bergerak di usaha tani kelapa sawit membangun kebun inti untuk perusahaan dan kebun plasma untuk masyarakat transmigrasi dan Masyarakat setempat.

Masyarakat yang ikut dalam program perkebunan kelapa sawit disebut petani plasma. Peserta petani plasma adalah masyarakat Jawa yang ikut transmigrasi ke daerah Kuamang Kuning pada tahun 1980. Pada awalnya masyarakat transmigrasi tersebut diberikan $2 \mathrm{Ha}$ lahan kebun, 0,75 Ha. lahan pangan, dan 0,25 Ha. lahan pekarangan termasuk rumah tempat tinggal peserta transmigrasi tersebut. Awal kegiatan usaha tani kelapa sawit, setiap peserta plasma bergabung dengan perusahaan inti untuk melakukan kegiatan perkebunan kelapa sawit. Selama 4 tahun pertama petani kelapa sawit yang belum menghasilkan hasil produksi, peserta transmigrasi (petani) tersebut diharuskan berkerja sebagai karyawan Perusahaan Inti Rakyat yang bertanggung jawab terhadap kebun masing-masing. Setelah 4 tahun saat kebun sudah mulai menghasilkan, lahan yang diperuntukan untuk transmigrasi dikonversi menjadi hak milik masing-masing. Sejak lahan dikonversi kepada masing-masing petani, untuk selanjutnya tanggung jawab penuh berada pada masing-masing petani, antara lain: perawatan kebun, pemupukan, 
penyediaan sarana produksi, penyediaan mesin dan alat pertanian, panen tandan buah segar (TBS). Sementara biaya pembangunan kebun yang dilakukan oleh perusahaan dicicil oleh petani setiap bulan melalui pemotongan penjualan buah (TBS). Setiap bulan penghasilan dipotong oleh perusahaan sebesar sepertiga dari penghasilan kebunnya, hal tersebut berjalan sampai hutang petani lunas.

Karena itu, perkebunan kelapa sawit menjadi alternatif pekerjaan dan penghasilan di perdesaan. Di perkebunan kelapa sawit orang bisa bekerja di sektor seperti menebas, menyemprot, memupuk, menunas kelapa sawit dan memanen. Untuk kategori ini biasanya tidak memerlukan ijazah karena bekerja hanya memerlukan tenaga dan keseriusan.

Banyak nya perusahan dan petani yang membudidayakan kelapa sawit membuat para petani harus pintar-pintar dalam mengatur startegi politik, agar hasil buah kelapa sawit memenuhi standar dan dapat terus di produksi oleh perusahaan yang mengolah buah kelapa sawit.

Tabel 1. Rekapitulasi Data Kelompok Tani yang Membudidayakan Kelapa Sawit di Kabupaten Bungo Tahun 2015

\begin{tabular}{|c|c|c|c|c|c|c|c|}
\hline No & Kecamatan & Juml & Kelompok & & & Total & Nama Kepala \\
\hline 1. & $\begin{array}{l}\text { Bathin II } \\
\text { Bebeko }\end{array}$ & $\begin{array}{l}\text { Bdk } \\
-\end{array}$ & $\begin{array}{l}\text { Pemula } \\
39\end{array}$ & $\begin{array}{l}\text { Lanjut } \\
-\end{array}$ & $\begin{array}{l}\text { Madya } \\
1\end{array}$ & 40 & $\begin{array}{l}\text { Uptb_Bp3k } \\
\text { Rinto Subagio }\end{array}$ \\
\hline 2. & Jujuhan Ilir & - & 22 & 22 & 7 & 51 & Sugiono,A.Md \\
\hline 3. & Bathin III Ulu & - & 62 & 4 & - & 66 & Saubri \\
\hline 4. & $\begin{array}{l}\text { Muko-Muko } \\
\text { Bathin VII }\end{array}$ & - & 31 & 5 & - & 36 & M.Adli, SPKP \\
\hline 5. & Bungo Dani & - & 23 & 1 & - & 24 & Bambang Eko \\
\hline 6. & $\begin{array}{l}\text { Rimbo } \\
\text { Tengah }\end{array}$ & - & 21 & 2 & - & 23 & Bambang Sunaryo \\
\hline 7. & Bathin III & - & 32 & 5 & 1 & 38 & Bety Sinaga \\
\hline 8. & $\begin{array}{l}\text { Pasar Muara } \\
\text { Bungo }\end{array}$ & - & 7 & 4 & - & 11 & Yeni Efrida \\
\hline 9. & $\begin{array}{l}\text { Tanah } \\
\text { Sepenggal } \\
\text { Lintas }\end{array}$ & - & 52 & 5 & - & 57 & Amri, S.ST \\
\hline 10. & $\begin{array}{l}\text { Tanah } \\
\text { Sepenggal }\end{array}$ & - & 57 & 19 & 1 & 77 & Edi Sucipto \\
\hline 11. & Jujuhan & - & 91 & 6 & - & 97 & Amrizal \\
\hline 12. & $\begin{array}{l}\text { Limbur Lubuk } \\
\text { Mengkuang }\end{array}$ & - & 116 & 14 & 3 & 133 & Prayitno, SP \\
\hline 13. & $\begin{array}{l}\text { Tanah } \\
\text { Tumbuh }\end{array}$ & - & 58 & - & - & 58 & Dahrizal, Amd \\
\hline 14. & $\begin{array}{l}\text { Bathin II } \\
\text { Pelayang }\end{array}$ & - & 30 & 1 & - & 31 & Marsup, SPKP \\
\hline 15. & $\begin{array}{l}\text { Rantau } \\
\text { Pandan }\end{array}$ & - & 34 & 10 & - & 44 & Cik Ruman \\
\hline 16. & Pelepat Ilir & - & 335 & 11 & - & 346 & Rusmen \\
\hline 17. & Pelepat & - & 108 & 10 & 3 & 121 & Aprijal, SPKP \\
\hline & JUMLAH & - & 1118 & 119 & 16 & 1253 & \\
\hline
\end{tabular}

Sumber: Badan Pelaksanaan Penyuluhan Pertanian, Perikanan, dan Kehutanan Kabupaten Bungo Tahun 2015 
Dari Rekapitulasi Data Kelompok Tani yang membudidayakan Kelapa sawit Kabupaten Bungo dapat dilihat bahwa banyak nya petani yang membudidayakan Tanaman Kelapa Sawit yang sangat signifikan dari tingkat Petani BDK , Pemula, Madya, hingga Lanjut mencapai 1000 lebih Petani se-Kabupaten Bungo yang ikut serta dalam membudidayakan tanaman Kelapa Sawit. Dari Tabel diatas, dapat di lihat bahwa yang paling signifikan adalah petani PEMULA yang mendominasi angka paling tertinggi.

Dari data kelompok tani yang ada di Kec. Pelepat Ilir dapat kita lihat bahwa Banyak nya petani pemula yang membudidayakan tanaman kelapa sawit, membuat petani harus jeli dan pintar dalam mengatur strategi. Selain itu, belum adanya kekuatan politik petani dan belum adanya organisasi dari petani membuat para petani kesulitan untuk mempertahankan harga jual, selama ini petani hanya bisa menerima kebijakan-kebijakan yang dibuat oleh perusahaan ataupun pemerintah. Petani hanya menjadi sasaran objek bagi orang-orang yang mengatur kebijakan. Dengan demikian, hal ini sangat membuat penulis tertarik untuk mengangkat judul ini dengan lebih jauh, dengan memilih judul sebagai berikut:"Strategi Petani Membangun Kekuatan Politik Petani Subsektor Perkebunan Komoditi Kelapa Sawit di Kecamatan Pelepat Ilir Kabupaten Bungo."

\section{Pembahasan}

Strategi petani dalam membangun kekuatan politik petani Subsektor
perkebunan komoditi kelapa sawit Kabupaten Bungo (studi Kasus Pelepat Ilir)

Strategi merupakan cara yang digunakan oleh seseorang atau kelompok untuk mencapai tujuan yang diharapkan. Strategi politik pada dasarnya membutuhkan perencanaan yang matang agar kesalahan-kesalahan yang mungkin terjadi dapat di hindari. Hal inilah yang menjadi landasan dalam perencanaan strategi petani dalam membangun kekuatan politik.Setelah membentuk tim ataupun kelompok, maka strategi selanjut dilaksanakan oleh tim ataupun kelompok itu sendiri. Dalam strategi politik dilihat dari konteks aktivitas politik, para petani juga membutuhkan adanya pemasaran politik.

Dari konteks aktivitas politik, pemasaran politik dimaksudkan adalah penyebar luasan informasi tentang hasil kelapa sawit itu sendiri, program ini dilakukan oleh tim ataupun kelompok petani melalui saluran-saluran komunikasi ataupun beberapa masyarakat yang telah bekerja pada instansi pemerintahan tertentu yang ditujukan kepada sasaran tertentu dengan tujuan menambah wawasan, pengetahuan, tentang kelapa sawit agar harga jua ltidak anjlok.

Seperti yang dikemukaka noleh Bruce I. Newman dan Richard M. Perloff dalam tulisannya, mendefinisikan pemasaran politik sebagai aplikasi prinsip-prinsip pemasaran dalam mengkampanye politik yang beranekaragam individu, organisasi, prosedur-prosedur, dan melibatkan analisis, pengembangan, eksekusi, dan strategi manajemen kampanye oleh kandidat, pemerintah, petani, kelompok kelompok tertentu yang biasa digunakan untuk mengarahkan opini public terhadap ideology mereka untuk membantu agar tujuannya tercapai.

Beberapa cara atau strategi yang digunakan petani dalam membangun kekuatan politik petani dalam subsector perkebunan kelapa sawit adalah sebagai berikut :

\section{A. Strategi Komunikasi}

Strategi adalah proses penentuan rencana para pemimpin puncak yang berfokus pada tujuan jangka panjang organisasi, disertai penyusunan suatu cara atau upaya bagaimana agar tujuan tersebut dapat dicapai. Strategi merupakan tindakan yang bersifat incremental yaitu sifat yang senantiasa meningkat dan terus menerus, serta dilakukan berdasarkan sudut pandang tentang apa yang dihadapkan di masadepan. Dengan demikian strategi hampir 
selalu dimulai dari apa yang dapat terjadi dan bukan dimulai dari apa yang terjadi.

Menurut Zein $(2008,109)$ bahwa strategi komunikasi adalah rencana yang meliputi metode, teknik dan tata cara hubungan fungsional antara unsurunsur dan faktor-faktor dari proses komunikasi, guna kegiatan operational antara unsur-unsur dan faktor-faktor dari proses komunikasi untuk mencapai tujuan dan sasaran. Dalam hal ini, Strategi komunikasi merupakan suatu cara yang digunakan oleh petani untuk memperoleh harga kelapa sawit yang tinggi, dukungan dari setiap petani pada saat ini sangat penting. Strategi komunikasi yang digunakan para petani dalam membangun kekuatan politik petani subsektor komoditi perkebunan kelapa sawit berdasarkan pernyataan 1 informan dalam wawancara dengan penulis, meliputi beberapa hal yaitu jaringan kekuasaan, sosialisasi.

\section{Jaringan Kekuasaan, dan sosialisasi}

Kekuasaan yang dimaksud adalah kekuasaan yang dimiliki oleh salah satu keluarga ataupun anggota kelompok para petani yang ada di kecamatan Pelepat Ilir yang tergabung dalam organisasi di dalam kelompok tani tersebut baik di tingkat struktural birokrasi (Pemerintah Kota, Kecamatan, Kelurahan bahkan hingga pengurus RT-RW), elite pengusaha, elite dilingkungan kepengurusan organisasi tertinggi hingga elite di dalam kelompok pendukung (supporter) rakyat baik petani maupun yang lainnya.

Beberapa informasi tersebut jejaring kekuasaan yang dimanfaatkan para petani memiliki pengaruh besar terhadap para petani kelapa sawit. Berbagai kelompok elite lokal yang berhasil dihimpun mempermudah mereka dalam memyampaikan aspirasi mereka kepada pemerintah daerah agar bisa membantu para petani kelapa sawit agar harga kelapa sawit tidak anjlok.Dalam artian bahwa berdasarkan berbagai informasi yang diperoleh nampak bahwa sejauh ini para petani sudah mulai menghidupkan kembali organisasi yang sempat tidak berjalan.

\section{B. Strategi Pembentukan Organisasi}

Pada hakekatnya kelompok tani adalah organisasi yang memiliki fungsi sebagai media musyawarah petani. Di samping itu, organisasi ini juga memiliki peran dalam akselerasi kegiatan program pembangunan pertanian. Kelompok tani dibentuk oleh dan untuk petani, guna mengatasi masalah bersama dalam usaha tani. Pada saat ini kelompok tani diperbesar menjadi gabungan kelompok tani pada satu wilayah administratif tertentu atau dikenal dengan istilah Gabungan Kelompok Tani (Gapoktan). Berdasarkan Keputusan Menteri Pertanian Nomor 93/Kpts/OT.210/3/1997 tentang pedoman Pembinaan Kelompok Tani-Nelayan. Gabungan Kelompok tani adalah merupakan gabungan dari beberapa kelompok tani yang melakukan usaha agribisnis di atas prinsip kebersamaan dan kemitraan sehingga mencapai peningkatan produksi dan pendapatan usaha tani bagi anggotanya dan petani lainnya. Selain itu, beberapa pihak pemerintahan juga menganjurkan agar para petani membentuk sebuah kelompok tani ataupun organisasi yang di naungi oleh para petani kelapa sawit agar dapat membentuk suatu kekuatan.

Berdasarkan pernyataan dari beberapa sumber baik petani maupun instansi pemerintahan di atas, dapat kita simpulkan bahwa Secara konseptual peran kelompok tani sangat lah penting itu semua merupakan suatu gambaran tentang bagaimana kegiatan-kegiatan kelompok tani yang dikelola berdasarkan kesepakatan anggotanya. Kegiatan tersebut dapat berdasarkan jenis usaha, 
atau unsur-unsur subsistem agribisnis, seperti pengadaan sarana produksi, pemasaran, penginformasian tentang harga pasar,pasca panen, pengolahan hasil panen dan sebagainya. Pemilihan kegiatan kelompok tani ini sangat tergantung pada kesamaan kepentingan, sumberdaya alam, sosial ekonomi, keakraban, saling mempercayai, dan keserasian hubungan antar petani, sehingga dapat merupakan faktor pengikat untuk kelestarian kehidupan berkelompok, dimana tiap anggota kelompok dapat merasa memiliki dan menikmati manfaat sebesar-besarnya dari kelompok tani.

Peranan kelompok tani juga dapat dimainkan tiap waktu oleh pemimpin kelompok maupun oleh anggota lainnya. Pemimpin kelompok tani memiliki peran sebagai koordinator, dimana mereka yang menjelaskan atau menunjukkan hubungan antara berbagai pendapat dan saran, sementara tiap anggota dalam kelompok tertentu boleh memainkan lebih dari satu peran dalam partisipasi kelompok. Disamping itu, pemimpin kelompok juga sebagai penggerak kelompok untuk bertindak atau mengambil keputusan, dan berusaha memberi semangat ada kelompok tani.

Meningkatnya partisipasi anggota kelompok akan meningkatkan kedinamisan kelompok. Kedinamisan kelompok tersebut akan memberikan peluang sebesar-besarnya kepada anggota untuk bekerjasama dan berpartisipasi dalam kegiatan kelompok, sehingga tujuan bersama dapat dicapai. Kelompok tani yang dinamis ditandai oleh selalu adanya kegiatan ataupun interaksi, baik di dalam maupun dengan pihak luar dalam upaya mencapai tujuan kelompok.

Sebagai organisai sosial masyarakat, kelompok tani berfungsi sebagai wadah belajar mengajar bagi anggotanya guna meningkatkan pengetahuan, keterampilan, dan sikap serta tumbuh dan berkembangnya kemandirian dalam berusahatani dengan produktivitas yang meningkat, pendapatan yang bertambah, dan kehidupan lebih sejahtera. Selain itu, kelompok tani juga berfungsi sebagai wahana kerjasama diantara sesama petani dalam kelompok tani dan antar kelompok tani, serta dengan pihak lain. Melalui kerjasama diharapkan usahataninya akan lebih efisien serta lebih mampu menghadapi ancaman, tantangan, hambatan, dan gangguan. Terakhir kelompok tani juga berfungsi sebagai unit produksi, yang dilaksanakan oleh masing-masing anggota kelompok tani secara keseluruhan sebagai satu kesatuan usaha yang dapat dikembangkan 3 untuk mencapai skala ekonomi, baik dipandang dari segi kuantitas, kualitas maupun kontinuitas. Adapun nama organisasi ataupun kelompok tani yang ada di kecamatan Pelepat Ilir antara lain sebagai berikut :

Tabel 2. Daftar Nama-Nama Kelompok Tani (Poktan) Sektor

Pertanian di Kabupaten Bungo Kecamatan Pelepat Ilir.

\begin{tabular}{|c|c|c|c|c|c|c|c|}
\hline \multirow{2}{*}{$\begin{array}{l}\text { Nama } \\
\text { Dusun/Desa }\end{array}$} & \multirow{2}{*}{$\begin{array}{l}\text { Nama } \\
\text { Kelompok } \\
\text { Tani }\end{array}$} & \multirow{2}{*}{$\begin{array}{l}\text { Kelas } \\
\text { Kelompok } \\
\text { Tani }\end{array}$} & \multicolumn{3}{|c|}{ Pengurus Kelompok } & \multirow{2}{*}{$\begin{array}{l}\text { Anggota } \\
\text { klpk }\end{array}$} & $\begin{array}{l}\text { Tahun } \\
\text { Berdir }\end{array}$ \\
\hline & & & $\begin{array}{l}\text { Ket. } \\
\text { kelompok }\end{array}$ & $\begin{array}{l}\text { Sekr. } \\
\text { kelompok }\end{array}$ & $\begin{array}{l}\text { Ben. } \\
\text { kelompok }\end{array}$ & & Berdir \\
\hline Purwo Sari & Karya Tani & Pemula & Sutisno & Rubiman & Sugiono & 20 & 1994 \\
\hline & langgeng & Pemula & Sumarto & Hendro & wardanu & 20 & 1995 \\
\hline & Temu sari & Pemula & Kayar R & Luyadi & Suwanto & 22 & 1994 \\
\hline & Murni jya & Pemula & Suwarjo & Suwardi & Simin & 18 & 1994 \\
\hline & Margo.M & Pemula & Sutawi & Minto & Yumadi & 18 & 1994 \\
\hline & Sumber.H & Pemula & Puryono & Utoyo & Iksan & 20 & 1994 \\
\hline & Hinayah & Pemula & Samidi & Hendra & Jupanto & 25 & 1994 \\
\hline & Makmur & Pemula & Imam & Kalimin & Jamiri & 25 & 1994 \\
\hline & SriJaya.M & Pemula & Sukeni & Sumadi & & 21 & 1994 \\
\hline & $\begin{array}{l}\text { Muncul } \\
\text { Makmur }\end{array}$ & Pemula & Slamet.r & Suhadi & Paiman & 24 & 1994 \\
\hline
\end{tabular}




\begin{tabular}{|c|c|c|c|c|c|c|c|}
\hline & Sidodadi & Pemula & Hartoyo & Sahiman & Saharudi & 24 & 1994 \\
\hline & Baroka & Pemula & Serkan & Suwarjo & Badau & 28 & 1994 \\
\hline & Rukun & Pemula & Suyadi & Sutawi & Suyadi.B & 18 & 1994 \\
\hline & Mekar Sari & Pemula & Wito & Kuyono & Kastidi & 24 & 1994 \\
\hline & Subur & $\begin{array}{l}\text { Pemula } \\
\text { pemula }\end{array}$ & Sumanto & $\begin{array}{l}\text { Burhanudi } \\
\text { n. B }\end{array}$ & Gunadi & 25 & 1994 \\
\hline & $\begin{array}{l}\text { Harapan } \\
\text { Jaya }\end{array}$ & Pemula & Kasmidi & Jupanto & Rusli & 23 & 1994 \\
\hline & Alhikmah & Pemula & Zainudin & Jamiri & Sanjaya & 27 & 1992 \\
\hline & Sari Sawit & Pemula & Supanto & Yudi & Rulianto & 26 & 1994 \\
\hline & $\begin{array}{l}\text { Sumber } \\
\text { Rezeki }\end{array}$ & Pemula & Jamin & Paimin & Suyanti & 19 & 1994 \\
\hline & Mekar lestari & Pemula & Suroto & $\begin{array}{l}\text { Imam } \\
\text { Shodik }\end{array}$ & Rumiani & 23 & 1994 \\
\hline & Berkat & Pemula & Paimin & Saharudin & Sukarno & 22 & 1995 \\
\hline & Tanjung Seto & Pemula & $\begin{array}{l}\text { Imam } \\
\text { sholih }\end{array}$ & Paimano & Daluyanti & 21 & 1994 \\
\hline & Melati & Pemula & Ali Sahar & Suyadi & Sutawi & 20 & 1994 \\
\hline & $\begin{array}{l}\text { Wijaya } \\
\text { Kusuma }\end{array}$ & Pemula & Pardiman & Kastidi & Puryono & 20 & 1994 \\
\hline & Mawar & Pemula & Khairul & Gunadi & Samidi.B & 27 & 1996 \\
\hline & Anggrek & Pemula & Sri solanus & $\begin{array}{l}\text { Ani } \\
\text { maryani }\end{array}$ & $\begin{array}{l}\text { Imam } \\
\text { Mulyani }\end{array}$ & 23 & 1994 \\
\hline Lembah & Wisnu & Pemula & Wardoyo & Mukhadi & Sugino & 22 & 1995 \\
\hline & Gareng & Pemula & Sumanto & Hartoyo & Hendro & 21 & 1994 \\
\hline & Tresno & Pemula & Sarjito & Suyadi & Sukardi & 18 & 1994 \\
\hline & Sedewo & Pemula & Sukamto & Mito & Wimto & 20 & 1994 \\
\hline & Gatotkoco & Pemula & Yumani & Zainudi & Kalimin & 21 & 1996 \\
\hline & Janoko & Pemula & Sumar & Sumanto & Utoyo & 25 & 1994 \\
\hline & Bimo & Pemula & Simin & Kasmidi & Hendra & 25 & 1994 \\
\hline & Subawi & Pemula & Sanjaya & Suroto & Mulyadi & 24 & 1994 \\
\hline & Sungkini & Pemula & Sunjono & Paimin & Katiman & 28 & 1994 \\
\hline & Setiani & Pemula & Sukar & Sutawi & Sutarjo & 18 & 1994 \\
\hline & Ismoyo & Pemula & Riyanto & Sumanto & Burhan & 24 & 1993 \\
\hline & Abiyoso & Pemula & Daluyo & Kasmidi & Jup[anto & 25 & 1994 \\
\hline & Petruk & Pemula & Najib & Zainudin & Jamiri & 23 & 1994 \\
\hline & Usmono & Pemula & $\mathrm{Abu}$ & Supanto & Suyoto & 20 & 1994 \\
\hline & Arjuno & Pemula & Daluyo & paimanto & Suyanto & 18 & 1995 \\
\hline Sumber & Harapan & Pemula & Darnyati & Sumarno & Darkun & 20 & 1994 \\
\hline & $\begin{array}{l}\text { Jaya } \\
\text { Budidaya }\end{array}$ & Pemula & Paimin & Baharudn & Katiman & 20 & 1995 \\
\hline & Sejahtera & Pemula & Darjo & Paiman & Kastidi & 24 & 1994 \\
\hline & Bhineka & Pemula & Rosidin & Gunadi & Rumiani & 23 & 1994 \\
\hline & Sukamaju & Pemula & Senen & Zainudin & Irman & 19 & 1996 \\
\hline & Suka damai & Pemula & Iswanto & $\begin{array}{l}\text { Slametmul } \\
\text { yono }\end{array}$ & Sukarno & 22 & 1995 \\
\hline & Tani maju & Pemula & Ngatino & Muihamm & Imam & 23 & 1994 \\
\hline & Pertada & Pemula & Bambang & - & - & 22 & 2003 \\
\hline & Setia bakti & Pemula & Tumirin & Sujoto & Mulyono & 18 & 1994 \\
\hline & Karya & Pemula & Walimin & Paiman & Baharudin & 20 & 1994 \\
\hline & $\begin{array}{l}\text { makmur } \\
\text { Suka maju } 2\end{array}$ & Pemula & Senen & zainudin & Imam & 19 & 1996 \\
\hline & Progo mulyo & Pemula & Suwarjo & Supanto & Sahardin & 24 & 1994 \\
\hline & Sidomuncul & Pemula & Sukarji & Jamin & Paimano & 24 & 1994 \\
\hline
\end{tabular}




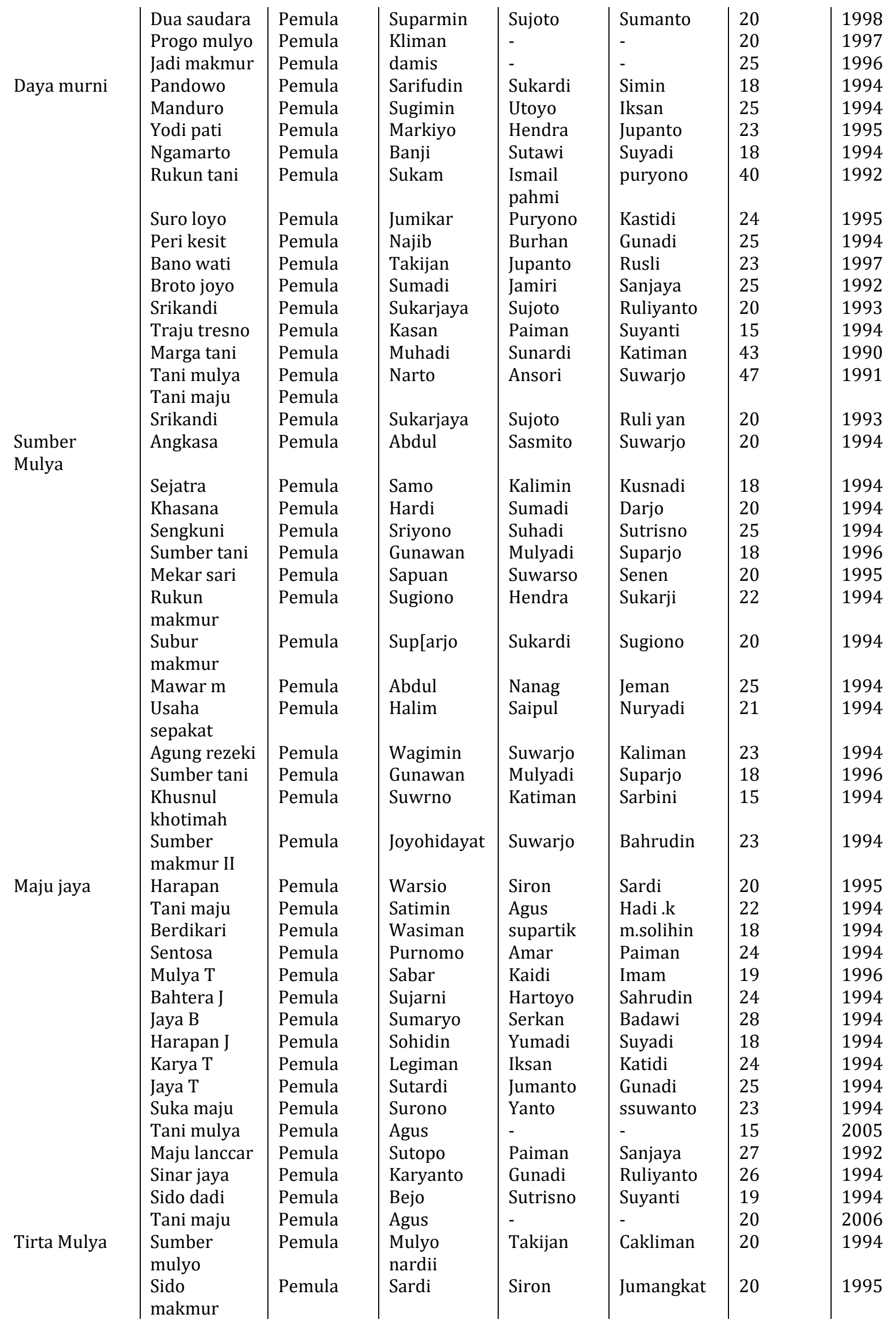




\begin{tabular}{|c|c|c|c|c|c|c|c|}
\hline & Garuda jaya & Pemula & m.sholihin & Partikno & Simin & 18 & 1994 \\
\hline & Subur jaya & Pemula & Surono & Heru & Yumadi & 18 & 1994 \\
\hline & Mukti tama & Pemula & Puji & Samingan & Jupanto & 25 & 1994 \\
\hline & Mukti jaya & Pemula & Misar & Agus & Jamiri & 25 & 1994 \\
\hline & Tunas muda & Pemula & Wayat & Sumino & Sujoto & 21 & 1994 \\
\hline & $\begin{array}{l}\text { Sumber } \\
\text { makmur }\end{array}$ & Pemula & Darno & Amar & Paiman & 24 & 1994 \\
\hline & Sido lancar & Pemula & Turwanto & Delvi & Imam & 19 & 1996 \\
\hline & $\begin{array}{l}\text { Bangun } \\
\text { hario }\end{array}$ & Pemula & Suryono & Sabar & Sahrudin & 24 & 1994 \\
\hline & Sumber sari & Pemula & Katiman & Banji & Badaw & 28 & 1994 \\
\hline & Adem ayem & Pemula & Sunardi & Jumukar & Suryadi & 18 & 1994 \\
\hline & $\begin{array}{l}\text { Harapan } \\
\text { baru }\end{array}$ & Pemula & Sumadi & Najib & Kastidi & 24 & 1994 \\
\hline & Sumber jaya & Pemula & Niken & Dermawan & Gunadi & 25 & 1994 \\
\hline & $\begin{array}{l}\text { Makarti } \\
\text { sawit }\end{array}$ & Pemula & Margono & Sukar & Sanjay & 27 & 1992 \\
\hline \multirow{13}{*}{$\begin{array}{l}\text { Lingga } \\
\text { kuamang }\end{array}$} & Setia kawan & Pemula & Dadang & Warsio & Wardanu & 20 & 1995 \\
\hline & Makmur & Pemula & Sukarno & Wasiman & Simin & 18 & 1994 \\
\hline & Mandiri jaya & Pemula & Yoko & Sujoko & Supanto & 25 & 1994 \\
\hline & Рерауа .p & Pemula & Suparno & Satimin & Suwanto & 22 & 1994 \\
\hline & $\begin{array}{l}\text { Sumber } \\
\text { rezeki }\end{array}$ & Pemula & Kedari & $\begin{array}{l}\text { Kasbiyant } \\
\text { o }\end{array}$ & Paimanto & 20 & 1994 \\
\hline & Harapan & Pemula & Sarmin & Lubis & Iksan & 20 & 1994 \\
\hline & Gudang & Pemula & Biarto & Asril & Jamiri & 25 & 1994 \\
\hline & $\begin{array}{l}\text { rejekl } \\
\text { Barokah }\end{array}$ & Pemula & Hadis & Yadi & Sujoto & 21 & 1994 \\
\hline & Tani jaya & Pemula & Makwan & Purnomo & Paiman & 21 & 1994 \\
\hline & Subur & Pemula & Muhadi & Sabar & Imam & 19 & 1996 \\
\hline & Setia maju & Pemula & Ade & Sujarni & Saharudin & 24 & 1994 \\
\hline & Sido rukun & Pemula & Bianto & sumaryant & Badawi & 28 & 1994 \\
\hline & Bina & Pemula & Jimo & Sohidin & Jumadi & 18 & 1994 \\
\hline \multirow[t]{19}{*}{ Bangun Harjo } & $\begin{array}{l}\text { makmur } \\
\text { Kakak tua }\end{array}$ & Pemula & Ansori & Jiron & Juman & 20 & 1995 \\
\hline & Murai & Pemula & Suwarno & saripudin & Suwaqnto & 20 & 1994 \\
\hline & Elang & Pemula & Sarono & Heru & Yumadi & 20 & 1994 \\
\hline & Gelatik & Pemula & Tukiman & Margio & Iksan & 20 & 1994 \\
\hline & Beo & Pemula & Ahmad & Samingan & Jupanto & 20 & 1994 \\
\hline & Perkutut & Pemula & Srimiyon & Agustris & Jamiri & 20 & 1994 \\
\hline & Belibis & Pemula & Srwo & Sumino & Sutojo & 20 & 1994 \\
\hline & Balam & Pemula & Sugito & Amar & Paiman & 20 & 1994 \\
\hline & Kutilang & Pemula & Sumardi & Delvi & Imam & 20 & 1996 \\
\hline & Garuda & Pemula & Supodo & Sabar & Sabarudn & 20 & 1994 \\
\hline & Semangka & Pemula & Sumardi & Najib & Kastidi & 20 & 1994 \\
\hline & Mangga & Pemula & Anis & Darmaw & gunadi & 20 & 1994 \\
\hline & Duku & Pemula & Firdaus & Sumadi & Rusli & 23 & 1994 \\
\hline & Pisang & pemula & Jasim & Sukar & Sanjaya & 19 & 1992 \\
\hline & Rambutan & Pemula & Ponim & Samidi & ruliyanto & 20 & 1994 \\
\hline & Apel & Pemula & Anis & Paiman & Suyanti & 18 & 1994 \\
\hline & Manggis & Pemula & Eko & Imam & Rumiani & 18 & 1994 \\
\hline & Durian & Pemula & Purnomo & saharudin & sukarno & 17 & 1995 \\
\hline & Delima & Poemula & Shokeh & Paiman & Dwi & 18 & 1994 \\
\hline \multirow{2}{*}{$\begin{array}{l}\text { Kuning } \\
\text { Gading }\end{array}$} & Betet & Pemula & Sarjo & Sajiwo & Mulyono & 20 & 1994 \\
\hline & Walet & Pemula & Suparlan & Misbahudi & Talib & 20 & 1995 \\
\hline
\end{tabular}




\begin{tabular}{|c|c|c|c|c|c|c|c|}
\hline & Sriti & Pemula & Sartono & Wandi & Suwanto & 20 & 1994 \\
\hline & Kacer & Pemula & Muslinin & Saripudin & Suimin & 20 & 1994 \\
\hline & Punai & Pemula & Sido & Naslim & Yumadi & 20 & 1994 \\
\hline & Nuri & Pemula & Mustakm & Sugimin & Iksan & 20 & 1994 \\
\hline & Manyar & Pemula & Suharto & Makiyo & Jupanto & 20 & 1994 \\
\hline & Poksai & Pemula & Budharjo & Samingan & Jamiri & 20 & 1994 \\
\hline & Pipit & Pemula & Mahasin & Agustris & Sujoto & 20 & 1994 \\
\hline & Rangkok & Pemula & Wahyono & Sumino & Paiman & 20 & 1994 \\
\hline & Cucok rowo & Pemula & Fadilah & Amar & lasimin & 20 & 1996 \\
\hline & Merak & Pemula & Budi & Puryadi & sharudin & 20 & 1994 \\
\hline & Leo & Pemula & Jumadi & Salam & jumngkir & 20 & 1994 \\
\hline & Cendrawasih & Pemula & Nasil & Banji & Suyadi & 20 & 1994 \\
\hline & Merpati & Pemula & Ngatimin & & & 20 & 1994 \\
\hline & Perkutut & Pemula & Tanto & & & 20 & 1994 \\
\hline & Camar & Pemula & Narto & & & 23 & 1992 \\
\hline & Rajawali & Pemula & Misron & & & 19 & 1994 \\
\hline & Benteng & Pemula & Jojo & & & 20 & 2001 \\
\hline & Setia mukti & Pemula & Sehenddra & & & 20 & 2002 \\
\hline & Beringinm & Pemula & Sudarjo & & & 21 & 2000 \\
\hline & Sumber & Pemula & Hadi & & & 22 & 2000 \\
\hline & $\begin{array}{l}\text { rejekl } \\
\text { Setia jaya }\end{array}$ & Pemula & Hasad & |- & - & 14 & \\
\hline & Apatir & Pemula & & - & & - & - \\
\hline Kuamang Jaya & $\begin{array}{l}\text { Gununceng } \\
\text { Kembar }\end{array}$ & Pemula & Nurkulis & Sigianto & Mulyono & 20 & 1994 \\
\hline & Gunung & Pemula & Sadiman & Sutopo & Talib & 20 & 1995 \\
\hline & Gunung & Pemula & Ponijan & Sadiman & Ponari & 20 & 1994 \\
\hline & $\begin{array}{l}\text { Merapi } \\
\text { Gunung }\end{array}$ & Pemula & Pamo & Hadi & Sutiman & 20 & 1994 \\
\hline & himalaya & & & & & & \\
\hline & Gunung kawi & Pemula & Kadiman & Haryanto & Sutarjo & 20 & 1994 \\
\hline & $\begin{array}{l}\text { Gunung } \\
\text { krakatau }\end{array}$ & Pemula & Ujang & Sugiman & Iksan & 20 & 1994 \\
\hline & Gunung & Pemula & Sularno & Makiyo & Jupanto & 20 & 1994 \\
\hline & Gunung & Pemula & jamingan & Samiri & Suyatno & 20 & 1994 \\
\hline & $\begin{array}{l}\text { mababu } \\
\text { Gunung }\end{array}$ & Pemula & Nurkholis & agustris & Sujoto & 20 & 1994 \\
\hline & $\begin{array}{l}\text { salak } \\
\text { Gunung lawu }\end{array}$ & Pemula & Wanto & & & 20 & 1994 \\
\hline & $\begin{array}{l}\text { Gunung } \\
\text { galunggung }\end{array}$ & Pemula & Mulyono & & & 20 & 1994 \\
\hline & $\begin{array}{l}\text { Gunung } \\
\text { slamet }\end{array}$ & Pemula & Mujamil & & & 20 & 1994 \\
\hline & Gunung & Pemula & Suratman & & & 20 & 1994 \\
\hline & $\begin{array}{l}\text { pujiama } \\
\text { Gunung }\end{array}$ & Pemula & Jimyati & & & 20 & 1994 \\
\hline & $\begin{array}{l}\text { Singgalang } \\
\text { Gunung } \\
\text { sumbing }\end{array}$ & Pemula & Siswanto & & & 20 & 1994 \\
\hline & Kelud & Pemula & Harno & & & 20 & 1994 \\
\hline & Gunung & Pemula & Eko & & & 20 & 1994 \\
\hline & Gunung & Pemula & Sadiman & & & 20 & 1994 \\
\hline & $\begin{array}{l}\text { sindore } \\
\text { Gunung }\end{array}$ & Pemula & Supartdi & & & 20 & 1994 \\
\hline
\end{tabular}




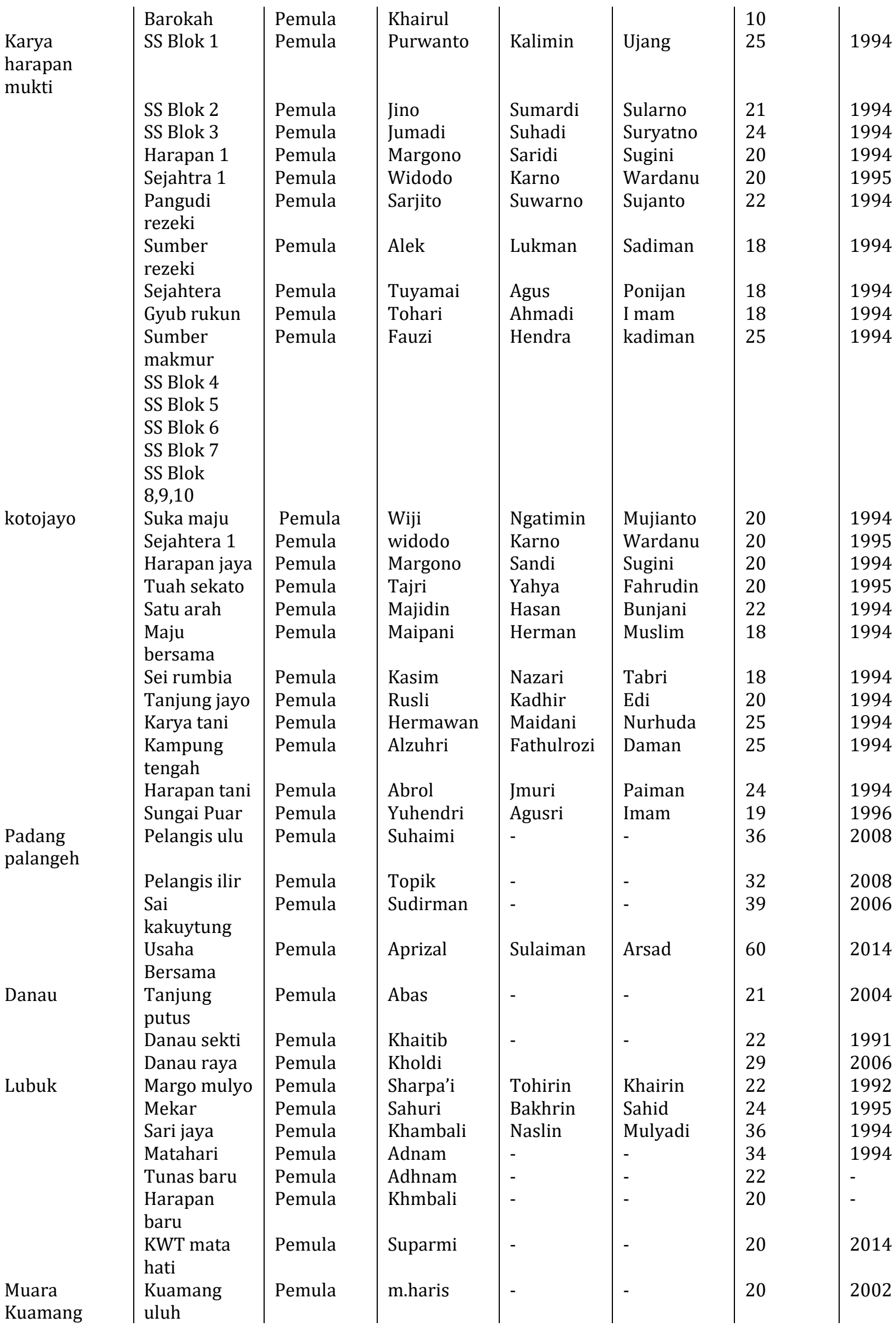




\begin{tabular}{|l|l|l|l|l|l|l}
$\begin{array}{l}\text { Danau } \\
\text { panjang } \\
\begin{array}{l}\text { Bungo } \\
\text { tanjung }\end{array}\end{array}$ & Pemula & m.ali & - & - & 21 & 1998 \\
& m.hayat & - & - & 25 & 2006
\end{tabular}

Sumber: Badan Pelaksanaan Penyuluhan Pertanian, Perikanan, dan Kehutanan Kabupaten Bungo Tahun 2016

Kendala-kendala yang di hadapi para petani dalam membangun kekuatan politik petani subsektor Perkebunan komoditi Kelapa Sawit di Kabupaten Bungo (studi Kasus Pelepat Ilir)

Dalam menjalankan strategi, para petani sering mendapatkan kendala-kendala dalam membangun kekuatan politik petani dalam subsektor perkebunan kelapa sawit antara lain; kurangnya kekompakan antar satu sama lain, tidak adanya pembinaan dari instansi terkait.

A. Kurangnya kekompakan terhadap satu sama lain

Didalam suatu kelompok atau organisasi tidak semua para petani yang setuju terhadap suatu keputusan yang dibuat oleh ketua kelompok maupun yang lain nya, hal inilah yang sering membuat para petani enggan untuk bergabung lagi dalam suatu organisasi. Kurang kompak nya suatu anggota organisasi membuat para petani sulit untuk menembus angka penjualan tertinggi karena itu semua akan membuat PT merasa bahwa petani tidak punya pilihan lain selain menjual kelapa sawit mereka pada PT tersebut.

B. Tidak adanya pembinaan dari Pemerintah Daerah

Kendala lain yang dihadapi para petani adalah kurangnya pembinaan ataupun penyuluhan terhadap para petani. Seperti yang kita tau bahwa Peran pembinaan ataupun penyuluhan merupakan suatu hal yang sangat penting bagi petani untuk mendukung kemajuan pertanian yang berkelanjutan dengan memfasilitasi petani dalam hal proses belajar, penyebaran informasi, pendampingan, pemecahan masalah, pembinaan, pemantauan, dan evaluasi terhadap kegiatan petani untuk mendukung terjadinya perubahan-perubahan kondisi sosial, politik dan ekonomi sehingga mereka dapat meningkatkan taraf hidup pribadi dan masyarakatnya. para petani sangat membutuhkan pembinaan ataupun penyuluhan dari instansi terkait agar mereka Penutup mendapatkan pelajaran dan semua informasi tentang kelapa sawit.

Berdasarkan uraian dan analisis yang telah di kemukakan pada bab-bab terdahulu, dalam bab ini peneliti dapat mengemukakan beberapa hal sebagai kesimpulan atas pokok permasalahan dalam penelitian ini, dan kemudian berusaha mengemukakan beberapa saran-saran guna terwujudnya Strategi Petani dalam membangun kekuatan politik petani subsektor komoditi kelapa sawit di kecamatan Pelepat Ilir. Kesimpulan dari penelitian ini adalah (1) Strategi komunikasi merupakan suatu cara yang digunakan oleh petani untuk memperoleh harga kelapa sawit yang tinggi, dukungan dari setiap petani pada saat ini sangat penting. Strategi komunikasi yang digunakan para petani dalam membangun kekuatan politik petani subsektor komoditi perkebunan kelapa sawit meliputi beberapa hal yaitu jaringan kekuasaan dan sosialisasi. Kekuasaan yang dimaksud adalah kekuasaan yang dimiliki oleh salah satu keluarga ataupun anggota kelompok para petani yang ada di kecamatan Pelepat Ilir yang tergabung dalam organisasi di dalam kelompok tani tersebut baik di tingkat struktural birokrasi (Pemerintah Kota, Kecamatan, Kelurahan bahkan hingga pengurus RT-RW), elite pengusaha, elite dilingkungan kepengurusan organisasi tertinggi hingga elite di dalam kelompok pendukung (supporter) rakyat baik petani maupun yang lainnya. Beberapa informasi tersebut jejaring kekuasaan yang dimanfaatkan para petani memiliki pengaruh besar terhadap para petani kelapa sawit. Berbagai kelompok elite lokal yang berhasil dihimpun mempermudah mereka dalam memyampaikan aspirasi mereka kepada 
pemerintah daerah agar bisa membantu para petani kelapa sawit agar harga kelapa sawit tidak anjlok (2) Pembentukan Organisasi. Pada hakekatnya kelompok tani adalah organisasi yang memiliki fungsi sebagai media musyawarah petani. Di samping itu, organisasi ini juga memiliki peran dalam akselerasi kegiatan program pembangunan pertanian. Kelompok tani dibentuk oleh dan untuk petani, guna mengatasi masalah bersama dalam usaha tani. Dengan adannya pembentukan organisasi ini, dapat Meningkatnya partisipasi anggota kelompok dan meningkatkan kedinamisan kelompok. Kedinamisan kelompok tersebut akan memberikan peluang sebesar-besarnya kepada anggota untuk bekerjasama dan berpartisipasi dalam kegiatan kelompok, sehingga tujuan bersama dapat dicapai. Kelompok tani yang dinamis ditandai oleh selalu adanya kegiatan ataupun interaksi, baik di dalam maupun dengan pihak luar dalam upaya mencapai tujuan kelompok. (3) kendala yang dihadapi para petani dalam membangun kekuatan politik petani subsektor perkebunan kelapa sawit di kecamatan Pelepat Ilir antara lain kurangnya kekompakan antar satu sama lain, tidak adanya pembinaan dari Pemerintah daerah.

Saran dari penulis adalah pemerintah daerah ataupun pemerintah pusat diharapkan mampu melihat pentingnya kegiatan pembinaan ataupun penyuluhan terhadap para petani kelapa sawit, penyuluhan ini merupakan suatu hal yang mendukung kemajuan pertanian yang berkelanjutan dengan memfasilitasi petani dalam hal proses belajar, penyebaran informasi, pendampingan, pemecahan masalah, pembinaan, pemantauan, dan evaluasi terhadap kegiatan petani untuk mendukung terjadinya perubahan-perubahan kondisi sosial, politik dan ekonomi sehingga mereka dapat meningkatkan taraf hidup pribadi dan masyarakatnya. Kegiatan penyuluhan yang dijalankan oleh instansi terkait sebaiknya lebih intensif dan maksimal, sehingga nantinya dapat meningkatkan keberdayaan petani khususnya petani swadaya, dan pada akhirnya terwujudnya suatu tujuan penyuluhan yang baik dan maksimal.

\section{Referensi}

Adimihardja, A. (2006). Strategi mempertahankan multifungsi pertanian di Indonesia. Jurnal Litbang Pertanian, 25(3), 99-105.

Budiardjo, Miriam. (1998). Dasar-Dasar Ilmu Politik. Grandmedia Pustaka Utama

Candra, Akbar. (2014). Kekuatan Politik Lokal Dalam Pemenangan Syahrul Yasir Limpi (SYL) Pada Pemilu Gubernur 2013 Daerah Pemilihan Kabupaten Gowa. Skripsi S-1: Universitas Hasanudin Semarang.

Dan, Nimmo. (2005). Komunikasi Politik. PT Remaja Rosdakarya

Elisabeth, J., \& Ginting, S. P. (2003). Pemanfaatan hasil samping industri kelapa sawit sebagai bahan pakan ternak sapi potong. Prosiding Lokakarya Nasional Sistem Integrasi Kelapa Sawit-Sapi. Bengkulu, 9-10.

Meleong, Lexy J. (2001). Metodologi Penelitian Kualitatif. PT Remaja Rosdakarya.

Nafis Kamil, Hadi. (2009). Militer dan Kekuatan Politik : Studi Tentang Keterlibatan TNI dalam Perpolitikan Nasional Era 1945-1998. Skripsi S-1: Universitas Islam Negeri Syarif Hidayatullah.

Nurani, Soyomuti. (2013). Komunikasi Politik. Intrans Publishing Pito, TA. (2006). Mengenal Teori - Teori Politik. Penerbit Nuansa Setyamidjaja dan Djoehana. (1991). Budidaya Kelapa sawit. Yogyakarta Siyamitri, P. (2009). Kondisi Kerja Karyawan Perempuan Perkebunan dan Hubungannya dengan Kesejahteraan Keluarga.

Sunarko. (2008). Petunjuk Praktis Budidaya dan Pengolahan Kelapa Sawit. Agromedia Pustaka, Sugiyono. (2012). Metode Penelitian Kuantitatif Kualitatif Dan R\&D, Cetakan ke-17. Alfabeta, Sutanto.(2011). Strategi Partai Demokrat dalam Pemenangan Pemilu Legislatif 2009 di Kota Semarang. Skripsi S-1: Universitas Negeri Semarang. 